\title{
Caracterização morfológica de variedades crioulas de abóboras (Cucurbita maxima) do sul do Brasil ${ }^{1}$
}

\author{
Daniela Priori ${ }^{2 *}$, Rosa Lía Barbieri ${ }^{2}$, Claudete Clarice Mistura ${ }^{2}$, Juliana Castelo Branco Villela ${ }^{2}$
}

10.1590/0034-737X201865040006

\begin{abstract}
RESUMO
O objetivo deste trabalho foi caracterizar morfologicamente variedades crioulas de Cucurbita maxima do sul do Brasil. Nove variedades crioulas de C. maxima foram caracterizadas com sete descritores quantitativos e 13 descritores qualitativos. As sementes foram cultivadas em casa de vegetação, em sacos de poliestireno preto, preenchidos com substrato. Quando as plantas apresentavam no mínimo duas folhas definitivas, 20 mudas de cada variedade foram transplantadas para o campo experimental, em delineamento completamente casualizado. Os dados quantitativos foram submetidos à análise de variância e foi utilizado o teste de Tukey para a comparação de médias, com o programa SAS 9.2. Os dados de caracteres quantitativos foram submetidos à análise de componentes principais, com o programa R. Para os caracteres qualitativos, a caracterização foi expressa pela moda de cada acesso, para cada descritor. Os caracteres qualitativos foram analisados como variáveis multicategóricas. A matriz de similaridade foi gerada no programa computacional GENES e foi construído um dendrograma, pelo método UPGMA, com o programa NTSYS. Ficou evidenciada a variabilidade genética para os caracteres quantitativos e qualitativos avaliados. A análise de variância evidenciou diferenças significativas entre as médias. Peso, formato, cor do fruto, espessura da casca e número de sementes por fruto são caracteres relevantes para a indicação de variedades crioulas promissoras para o melhoramento genético, com potencial para uso como fontes de genes e desenvolvimento de cultivares.
\end{abstract}

Palavras-chave: Cucurbitaceae; recursos genéticos; caracterização de germoplasma; descritores morfológicos.

\section{ABSTRACT}

\section{Morphological characterization of pumpkin landraces (Cucurbita maxima) from Southern Brazil}

The objective of this work was to morphologically characterize Cucurbita maxima landraces. Nine landraces were characterized by seven quantitative descriptors and 13 qualitative descriptors. The seeds were cultivated in black polystyrene bags filled with substrate in greenhouse. When the plants had at least two definitive leaves, 20 seedlings of each landrace were transplanted to the experimental field, spaced $2.5 \mathrm{~m}$ between plants and $4 \mathrm{~m}$ between rows, in a completely randomized design. Quantitative data were subjected to analysis of variance. Tukey test was used for the comparison of means, using the SAS 9.2 program. Data of quantitative traits were subjected to the principal component analysis, using the R program. For the qualitative traits, the characterization was expressed by the mode of each accession for each descriptor. Qualitative traits were analyzed as multicategorical variables. Similarity matrix was generated in the GENES program, and a dendrogram was constructed by the UPGMA method using the NTSYS program. Genetic variability was evidenced for the quantitative and qualitative traits evaluated. The analysis of variance showed significant differences between the means. Weight, shape, fruit color, bark thickness, and number of seeds per fruit are relevant characters to indicate promising landraces for breeding, with potential for use as sources of genes and development of cultivars.

Keywords: Cucurbitaceae; genetic resources; characterization of germplasm; morphological descriptors.

\footnotetext{
Submetido em 19/07/2017 e aprovado em 02/08/2018.

${ }^{1}$ Esse trabalho foi extraído da tese da primeira autora.

22 Embrapa Clima Temperado, Pelotas, Rio Grande do Sul, Brasil. dani_priori@yahoo.com.br; lia.barbieri@embrapa.br; c.mistura@hotmail.com; jcbrancov@gmail.com;

*Autora para correspondência: dani_priori@yahoo.com.br
} 


\section{INTRODUÇÃO}

De forma geral, no Brasil, os termos 'abóbora', 'moranga' e ‘jerimum' têm sido utilizados para designar espécies do gênero Cucurbita (Ramos et al., 2010a). Como há uma grande variação de nomes populares, de acordo com a região do país, Heiden et al. (2007) sugerem o uso do termo 'abóboras' para designar coletivamente as cinco espécies domesticadas de Cucurbita. As abóboras (Cucurbita spp.) são um alimento básico para a população brasileira, com importância socioeconômica e nutricional (Blank et al., 2013; Carvalho et al., 2011). Variedades crioulas das cinco espécies domesticadas (Cucurbita argyrosperma Huber., C. ficifolia Bouché, C. maxima Duchesne, C. moschata Duchesne e C. pepo L.) são cultivadas em diferentes regiões do país (Heiden et al., 2007). Todas as espécies do gênero Cucurbita são diploides, com 20 pares de cromossomos $(2 \mathrm{n}=40)$ (LiraSaade, 1995). Dentre as espécies cultivadas, a maior variabilidade genética ocorre em C. pepo, seguida por C. maxima (Whitaker \& Robinson, 1986; Hernandez et al., 2005).

Nas diferentes regiões do Brasil, a diversidade das espécies do gênero Cucurbita é mantida por agricultores familiares, que selecionaram as variedades adequadas as suas condições edafoclimáticas, durante gerações. A diversidade das espécies do gênero Cucurbita, especialmente C. moschata e C. maxima, é representada pelas inúmeras variedades crioulas cultivadas por indígenas, quilombolas e produtores da agricultura de base familiar, ao longo da história. Os fatores evolutivos (mutação, fluxo gênico, seleção e deriva genética) atuam continuamente sobre essas variedades crioulas, criando e ampliando a variabilidade de cada espécie. O fluxo gênico é garantido pela troca de sementes entre os agricultores (Ferreira, 2008).

As variedades crioulas são aquelas desenvolvidas pelos próprios agricultores, ao longo do tempo, cujas sementes são passadas de geração a geração e também trocadas entre vizinhos e parentes. Mais do que um patrimônio genético, essas variedades crioulas fazem parte de uma representação cultural, que inclui desde o nome dado a elas, até seu uso (Barbieri, 2012).

Apesar da crescente ameaça de erosão genética sobre essas variedades crioulas, seu cultivo é bastante característico. Na região nordeste do Brasil, há um cultivo mais intenso de $C$. moschata, enquanto $C$. maxima é pouco cultivada e as demais espécies de Cucurbita (C. pepo, $C$. argyrosperma e $C$. ficifolia) não o são. Em contrapartida, na região sul do Brasil, as cinco espécies domesticadas são produzidas e consumidas com maior destaque para $C$. maxima e C. moschata (Heiden et al., 2007). Cabe ressaltar que o híbrido Tetsukabuto é bastante produzido e consumido em grande parte do país (Nordeste, Sudeste, Sul), substituindo muitas vezes o cultivo das variedades criou- las. A perda desse germoplasma tradicional é preocupante e, por isso, têm grande importância as atividades de coleta, conservação ex situ, caracterização e avaliação dessas variedades, possibilitando a manutenção da variabilidade genética e sua disponibilidade para os programas de melhoramento (Cabral et al., 2010; Sudré et al., 2010; Oliveira et al., 2016).

Por apresentarem elevada variabilidade genética, para um grande número de caracteres, com genes de tolerância a estresses bióticos e abióticos, as variedades crioulas de Cucurbita são recursos genéticos importantes para o melhoramento. Apesar de esse germoplasma ser pouco estudado, sabe-se que oferece possibilidades interessantes para o desenvolvimento de novos cultivares com características desejáveis, como resistência a doenças, produtividade e qualidade nutricional dos frutos (Torres Filho, 2008; Lima, 2013).

O Banco Ativo de Germoplasma (BAG) de Cucurbitáceas, da Embrapa Clima Temperado, conserva 640 acessos de diferentes espécies cultivadas dos gêneros Citrullus, Cucumis, Cucurbita, Lagenaria, Luffa, Momordica e Sicana, sendo que 85 acessos são variedades crioulas de Cucurbita maxima. Porém, apenas uma pequena parte do acervo total do BAG já foi caracterizada (Neitzke et al., 2009; Priori, 2011; Priori, 2015; Fischer, 2012; Fischer et al., 2015; Fischer et al., 2016; Priori et al., 2012; Priori et al., 2013; Priori, et al., 2017). Para a realização deste trabalho, nove variedades crioulas de $C$. maxima foram selecionadas, seguindo-se alguns critérios, como a quantidade de sementes disponíveis no BAG e suficientes para a implantação do experimento, os dados de passaporte (como local de coleta, características dos frutos, reveladas pelos agricultores que doaram as sementes, como formato, cor da casca e tamanho dos frutos).

Este trabalho teve como objetivo caracterizar morfologicamente variedades crioulas de Cucurbita maxima do sul do Brasil.

\section{MATERIAL E MÉTODOS}

Foram avaliados nove acessos de variedades crioulas de abóboras (Cucurbita maxima), do Banco Ativo de Germoplasma de Cucurbitáceas, da Embrapa Clima Temperado. Na Tabela 1, estão listados os nove acessos de variedades crioulas avaliados, com nome popular, espécie e procedência.

As sementes foram cultivadas em sacos de poliestireno preto, preenchidos com substrato, em casa de vegetação. Quando as plantas apresentavam no mínimo duas folhas definitivas, 20 mudas de cada acesso foram transplantadas para o campo experimental, localizado na sede da Embrapa Clima Temperado, em Pelotas, RS, com espaçamento de 2,5 m entre plantas e $4 \mathrm{~m}$ entre linhas, em um 
delineamento completamente casualizado, considerandose cada planta como uma repetição. O solo foi preparado por meio de aração e gradagem e a adubação foi feita com NPK 04-14-08, incorporado ao sulco de plantio. A área de cultivo foi mantida limpa, com controle de plantas invasoras por capinas manuais. A irrigação por gotejamento foi realizada três vezes por semana, ou quando necessário. Não houve aplicação de fungicidas.

As plantas foram caracterizadas morfologicamente, utilizando-se sete descritores quantitativos e 13 descritores qualitativos, adaptados de Esquinas-Alcazar \& Gulick (1983). Os descritores quantitativos foram: comprimento do entrenó $(\mathrm{cm})$, número de frutos por planta, diâmetro do fruto $(\mathrm{cm})$, peso do fruto $(\mathrm{kg})$, espessura da casca $(\mathrm{mm})$, espessura da polpa $(\mathrm{cm})$, número de sementes por fruto e peso de 100 sementes (g). Os descritores qualitativos foram: formato do caule em secção transversal; formato da folha; tamanho da folha; formato do pedúnculo; formato do fruto; número de gomos no fruto; cor predominante da casca, na maturidade; cor secundária da casca; desenho produzido pela cor secundária; textura da casca; dureza da casca; cor da polpa e tamanho da semente.

Para cada acesso, foram submetidas à caracterização 20 plantas e cinco frutos por planta, conforme recomendado por Esquinas-Alcazar \& Gulick (1983). Os dados quantitativos foram submetidos à análise de variância (ANOVA) para comparação dos valores médios das variáveis. Ao verificar a existência de diferenças significativas entre os tratamentos, de acordo com o valor de $p$ associado ao teste $\mathrm{F}(\mathrm{p}<0,05)$, foi avaliada a magnitude dessas diferenças, utilizando-se o teste Tukey $(\mathrm{p}<0,05)$ para comparações múltiplas. As análises estatísticas foram realizadas com o programa computacional SAS 9.2 (Statistical Analysis System) (SAS Institute Inc., 2008).

Os dados de caracteres quantitativos também foram submetidos à análise de componentes principais. Neste caso, foi utilizada a análise multivariada para identificar as variedades crioulas mais semelhantes entre si e grupos com características distintas. A representação gráfica es-

Tabela 1: Variedades crioulas de Cucurbita maxima do Banco Ativo de Germoplasma de Cucurbitáceas, da Embrapa Clima Temperado

\begin{tabular}{lll}
\hline Acesso & \multicolumn{1}{c}{ Nome popular } & \multicolumn{1}{c}{ Procedência } \\
\hline C8 & moranga & Renascença, PR \\
C79 & abóbora mesclada & Farroupilha, RS \\
C92 & abóbora de casca branca & Ipê, RS \\
C253 & abóbora gigante & Não-Me-Toque, RS \\
C269 & abóbora & Piratini, RS \\
C273 & abóbora de casca laranja & Marcelino Ramos, RS \\
C282 & abóbora & Pelotas, RS \\
C288 & abóbora & Pelotas, RS \\
C347 & moranga de estouro & David Canabarro, RS \\
\hline
\end{tabular}

colhida foi a Biplot, na qual a ideia fundamental consiste em obter-se uma representação simultânea dos indivíduos e das variáveis, num espaço de baixa dimensão, que forneça informação útil para a compreensão da relação entre indivíduos e variáveis e entre indivíduos e os componentes principais dos dados. As análises estatísticas foram realizadas com o programa computacional $\mathrm{R}$ ( $\mathrm{R}$ Development Core Team, 2011). Para os caracteres qualitativos, a caracterização foi expressa por meio da moda de cada acesso, para cada descritor. Os caracteres qualitativos foram analisados como variáveis multicategóricas e a matriz de similaridade foi calculada por meio do índice:

$S_{\text {ii' }}=\frac{C}{C+D}$,

em que:

C: total de concordância de categorias para todas as variáveis consideradas;

D: total de discordância de categoria para todas as variáveis consideradas.

A matriz de similaridade foi gerada com o programa computacional GENES (Cruz, 2013). Com base na matriz de similaridade, foi construído um dendrograma, pelo método UPGMA com o programa NTSYS (Rohlf, 1989).

\section{RESULTADOS E DISCUSSÃO}

Ficou evidenciada a variabilidade genética para os caracteres quantitativos e qualitativos avaliados nas variedades crioulas de Cucurbita maxima. As médias apresentaram diferenças significativas para todos os caracteres quantitativos (Tabela 2).

As médias do comprimento do entrenó e da espessura da polpa também apresentaram diferenças significativas, conforme os valores mostrados na Tabela 2. Quanto à espessura da polpa, Martins (2015) encontrou valores entre 2,2 e 4,1 cm em variedades locais de Cucurbita maxima, conservadas e produzidas pela agricultura familiar na Amazônia. Os valores encontrados neste trabalho para espessura da polpa nos frutos foram mais altos que os constatados por Amaro et al. (2014), em híbridos de abóboras entre C. maxima e C. moschata, da Embrapa Hortaliças, cujo valor médio foi de 2,57 cm. Também foi maior que o encontrado por Nascimento et al. (2008), em híbridos de abóbora (C. maxima x C. moschata), de 2,64 cm. No entanto, foi inferior à espessura média encontrada por Balkaya et al. (2010), em frutos de C. maxima com valor foi de $3,49 \mathrm{~cm}$. Guzmán (2006) relatou variação para espessura da polpa em frutos de $C$. maxima de $1,5 \mathrm{~cm}$ a $12 \mathrm{~cm}$, maiores que os encontrados neste estudo. De acordo com Almeida et al. (1994), esta característica tem grande importância, pois maior percentagem de polpa implica maior aproveitamento do fruto. 
Com relação à espessura da casca, as variedades crioulas avaliadas apresentaram diferenças significativas para os valores encontrados, conforme descrito na Tabela 2. Amaro et al. (2014) não encontraram diferença significativa para espessura da casca em frutos de híbridos $(C$. maxima x $C$. moschata), cujos resultados variaram de 0,28 a 1,18 cm. Balkaya et al. (2010) avaliaram a variabilidade fenotípica de 115 populações de abóbora C. maxima, coletadas na região do Mar Negro, na Turquia, e encontraram valores mais elevados para espessura da casca que os deste estudo, variando de 2,9 a 9,0 mm. Conforme Barbosa (2009), frutos com espessura fina de casca favorecem a perda de massa durante o armazenamento, tanto pela maior vulnerabilidade à injúria mecânica quanto pela maior perda de água. As espessuras da casca e da polpa estão relacionadas com o rendimento da porção consumível do fruto. Espessuras intermediárias da casca, com valores entre 0,84 e $0,93 \mathrm{~mm}$, podem favorecer o armazenamento por períodos maiores, sem prejudicar o rendimento da polpa (Amaro et al., 2014). Segundo Balkaya et al. (2010), quando a casca apresenta espessura acima de $6 \mathrm{~mm}$, ela é considerada espessa; entre 4,3 mm e $6 \mathrm{~mm}$, medianamente espessa e, quando entre $2,9 \mathrm{~mm}$ e 4,3 $\mathrm{mm}$, fina.

Quanto ao peso de fruto, as variedades avaliadas diferiram significativamente (Tabela 2). Para essa variável, Guzmán (2006) encontrou valores próximos aos deste estudo, ao avaliar 224 acessos de $C$. maxima, com o valor médio de 9,2 kg, com variação de $1 \mathrm{~kg}$ até $25 \mathrm{~kg}$. Balkaya et al. (2010) encontraram, em populações de $C$. maxima, valor médio para peso de fruto de $7,4 \mathrm{~kg}$, com valores entre 3,2 e 11,8 kg. Marreiros et al. (2005) encontraram valores mais altos que os deste estudo, para variedades de $C$. maxima, de 3,5 kg a 16,6 kg. Martins (2015) encontrou, em variedades locais de C. maxima coletadas na Amazônia, valores mais baixos que os encontrados neste trabalho, de $1,36 \mathrm{~kg}$ a 2,47 kg. Ramos et al. (2010b) encontraram valores entre 5 e $8 \mathrm{~kg}$, em frutos de outra espécie de abóbora, a $C$. moschata, comercializados no interior da Bahia. A comercialização de frutos para consumo relaciona-se à matéria fresca (tamanho e peso do fruto), característica essencial de qualidade para o mercado consumidor. Há preferência por abóboras com matéria fresca de até $3 \mathrm{~kg}$. Evidencia-se, assim, a importância de se estudar e caracterizar essas variedades crioulas, mantidas nos bancos de germoplasma, para futuros lançamentos como cultivares comerciais e, também, para atender as exigências de mercado e dos consumidores. No Brasil, observa-se que, muitas vezes, abóboras de tamanho grande são comercializadas em pedaços ou fatias, em supermercados e feiras. Nesse caso, vários aspectos são levados em consideração pelo consumidor, um deles a cor da polpa: os frutos de polpa mais alaranjada sempre têm preferência.

Foi possível observar também variação para número de sementes por fruto e peso de 100 sementes, parâmetros quanto aos quais o acesso C253 foi destaque, apresentando os maiores valores (Tabela 2). Santos (2013), ao caracterizar cultivares de abóbora (C. moschata) relatou, para massa média de 100 sementes, valores de 8,26 g a 12,13 g.

A análise de componentes principais vem-se destacando como a metodologia mais empregada em bancos ou coleções de germoplasma, pois, além de identificar os caracteres mais importantes na contribuição para a variação total disponível entre os indivíduos analisados, fornece indicação para eliminar os que pouco contribuem (Dias et al., 1997; Alves, 2002). Os dois primeiros componentes explicaram 72,86\% da variação total disponível, sendo que as nove variedades de Cucurbita maxima avaliadas foram reunidas em cinco grupos (Figura 1). O grupo III apresenta notas mais elevadas para número de sementes por fruto, espessura da polpa, peso de fruto e diâmetro de fruto. $\mathrm{O}$ grupo II apresenta notas mais elevadas para o descritor comprimento do entrenó. Já o grupo IV apresenta valores elevados para espessura da casca e, o grupo V, valores elevados para peso de 100 sementes. Quando se analisam

Tabela 2: Médias dos descritores quantitativos em variedades crioulas de Cucurbita maxima do Banco Ativo de Germoplasma de Cucurbitáceas da Embrapa Clima Temperado

\begin{tabular}{lcccccc}
\hline Acesso & $\mathbf{C E}(\mathbf{c m})$ & $\mathbf{P F}(\mathbf{k g})$ & $\mathbf{E C}(\mathbf{m m})$ & $\mathbf{E P}(\mathbf{c m})$ & $\mathbf{N S F}$ & $\mathbf{P S}(\mathbf{g})$ \\
\hline C8 & $7,73 \mathrm{~cd}$ & $0,57 \mathrm{e}$ & $3,54 \mathrm{a}$ & $1,94 \mathrm{f}$ & $142,26 \mathrm{~d}$ & $22,48 \mathrm{a}$ \\
C79 & $5,95 \mathrm{de}$ & $2,26 \mathrm{~cd}$ & $1,71 \mathrm{~b}$ & $3,35 \mathrm{~cd}$ & $268,22 \mathrm{c}$ & $28,66 \mathrm{a}$ \\
C92 & $11,87 \mathrm{~b}$ & $1,40 \mathrm{de}$ & $1,07 \mathrm{c}$ & $3,08 \mathrm{~d}$ & $319,67 \mathrm{~b}$ & $26,72 \mathrm{a}$ \\
C253 & $7,09 \mathrm{~cd}$ & $12,31 \mathrm{a}$ & $0,93 \mathrm{c}$ & $5,04 \mathrm{a}$ & $558,46 \mathrm{a}$ & $57,85 \mathrm{~b}$ \\
C269 & $8,61 \mathrm{c}$ & $2,65 \mathrm{~cd}$ & $1,01 \mathrm{c}$ & $2,55 \mathrm{e}$ & $311,03 \mathrm{bc}$ & $37,95 \mathrm{a}$ \\
C273 & $4,07 \mathrm{e}$ & $3,47 \mathrm{bc}$ & $0,97 \mathrm{c}$ & $3,99 \mathrm{~b}$ & $271,98 \mathrm{bc}$ & $33,04 \mathrm{a}$ \\
C282 & $4,65 \mathrm{e}$ & $2,77 \mathrm{bcd}$ & $1,09 \mathrm{c}$ & $2,59 \mathrm{e}$ & $173,36 \mathrm{~d}$ & $20,20 \mathrm{a}$ \\
C288 & $4,48 \mathrm{e}$ & $4,12 \mathrm{~b}$ & $0,95 \mathrm{c}$ & $3,63 \mathrm{bc}$ & $320,27 \mathrm{~b}$ & $40,81 \mathrm{a}$ \\
C347 & $15,76 \mathrm{a}$ & $0,55 \mathrm{e}$ & $0,83 \mathrm{c}$ & $1,91 \mathrm{f}$ & $142,33 \mathrm{~d}$ & $20,19 \mathrm{a}$ \\
\hline
\end{tabular}

Médias seguidas pela mesma letra, em cada coluna, não diferiram significativamente entre si pelo teste de Tukey $(\mathrm{p} \geq 0,05)$. CE: Comprimento do entrenó; PF: Peso do fruto; EC: Espessura da casca; EP: Espessura da polpa; NSF: Número de semente por fruto; PS: Peso de 100 sementes.

Rev. Ceres, Viçosa, v. 65, n.4, p. 337-345, jul/ago, 2018 
as setas no gráfico biplot, ângulos menores, maiores e iguais a $90^{\circ}$ graus indicam associação positiva, negativa e ausência de associação, respectivamente (Yan, 2001).

A análise de componentes principais tem sido utilizada em Cucurbita por outros autores. Borges et al. (2011) verificaram a formação de grupos distintos, ao estimarem a divergência genética, em 16 acessos de abóbora $(C$. moschata) do Banco Ativo de Germoplasma de Cucurbitáceas, da Embrapa Semiárido, com base em caracterizações morfológica e agronômica, para orientar trabalhos de melhoramento genético com a espécie em que as variáveis que contribuíram para a divergência genética foram diâmetro médio, peso médio e comprimento médio do fruto. Balkaya et al. (2010) também obtiveram diferentes agrupamentos, ao avaliarem acessos de C. maxima, utilizando a análise de componentes principais em que as variáveis peso e comprimento do fruto, comprimento da semente, espessura da polpa, espessura da casca e sólidos solúveis totais foram as que mais contribuíram para a divergência genética entre os acessos.

À direita do gráfico (Figura 1) foi formado o grupo IV, no qual está presente a variedade crioula C8 (Figura 2D), que se diferenciou das demais pela espessura da casca. C8 apresenta frutos pequenos e é bastante produtiva, com o maior número de frutos dentre todas as variedades estudadas. Frutos de tamanho reduzido (como aqueles produzidos pelo acesso C8) são ideais para consumidores que moram sozinhos ou para famílias pequenas, por fornecerem a quantidade adequada ao consumo. Para o consumi-

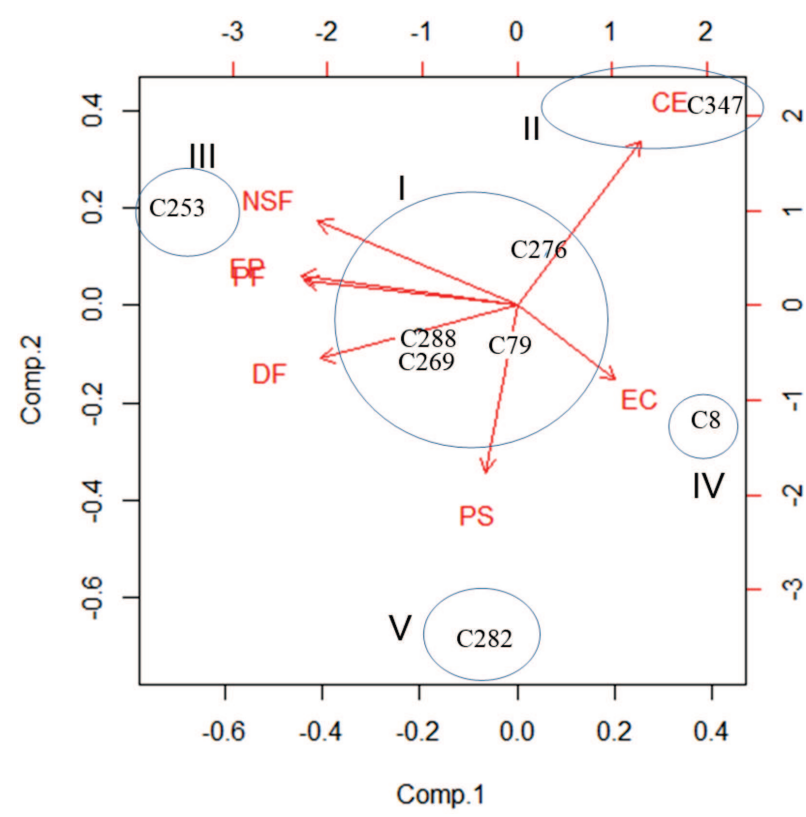

Figura 1: Agrupamentos de nove variedades crioulas de Cucurbita maxima, obtidos pela análise de componentes principais, em representação gráfica do tipo biplot. CE: comprimento do entrenó; PF: peso de fruto; EC: espessura da casca; EP: espessura da polpa; NSF: número de sementes por fruto; PS: peso de 100 sementes; DF: diâmetro do fruto. dor, a vantagem em adquirir frutos pequenos em vez de frutos fatiados reside no fato de que os primeiros têm uma durabilidade muito maior, enquanto os últimos devem ser consumidos com maior brevidade. Em avaliações anteriores (dados não publicados), o acesso C8 evidenciou polpa muito saborosa e consistente, com durabilidade pós-colheita ultrapassando 12 meses. A caracterização realizada neste trabalho serviu de base para a tomada de decisão quanto ao cadastramento desse acesso no Registro Nacional de Cultivares, do Ministério da Agricultura, Pecuária e Abastecimento (RNC/MAPA). Após alguns ciclos de seleções massais para padronização do formato e tamanho de frutos, o acesso C8 foi registrado como o cultivar BRS Tortéi. O lançamento desse cultivar aconteceu em 2013. As sementes da BRS Tortéi são produzidas e comercializadas pela Bionatur (empresa de sementes agroecológicas).

A esquerda do gráfico (Figura 1) foi formado o grupo III, no qual está presente o acesso C253 (Figura 2A). Esse acesso diferenciou-se dos demais pelo número de sementes por fruto, pela espessura da polpa, pelo peso e diâmetro do fruto. Frutos de tamanho grande (como aqueles produzidos pelo acesso C253) são adequados para o processamento em agroindústrias, por fornecerem grande quantidade de matéria-prima.

Na Figura 1, os caracteres espessura da casca e número de sementes por fruto apresentaram correlação negativa, pelo sentido inverso das setas. Esses dois caracteres foram os que contribuíram para separar em grupos isolados as variedades crioulas C8 e C253. Essas duas variedades ficaram em grupos distintos no dendrograma de similaridade genética (Figura 3), com base em caracteres qualitativos dos frutos. Trabalhos relatados na literatura mostram alta variabilidade genética em variedades locais de Cucurbita, incluindo variações de forma, tamanho e cor de frutos, número e tamanho de sementes, cor e espessura da polpa (Nerson et al., 2000; Ferriol et al., 2003; Paksoy \& Aydin, 2004; Hernandez et al., 2005). Essas informações são muito importantes e úteis para programas de melhoramento genético. $\mathrm{O}$ alto grau de variabilidade genética está relacionado também com o sistema reprodutivo da espécie (Geleta et al., 2005). A abóbora é alógama, reproduz-se por fecundação cruzada e possui hábito de florescimento monoico, o qual contribui para o aumento da variabilidade genética das espécies (Ferreira, 2008; Nick \& Borém, 2017).

Para os caracteres qualitativos avaliados, o formato do fruto e a cor da casca foram os que apresentaram maior variação (Figura 2). Os formatos dos frutos variaram entre globulares, achatados e alongados (Tabela 3). Balkaya et al. (2010) também encontraram variação para formato de fruto em C. maxima. O maior número de acessos apresentou formato globular $(49,6 \%)$, seguido de oval $(28,2 \%)$ e 

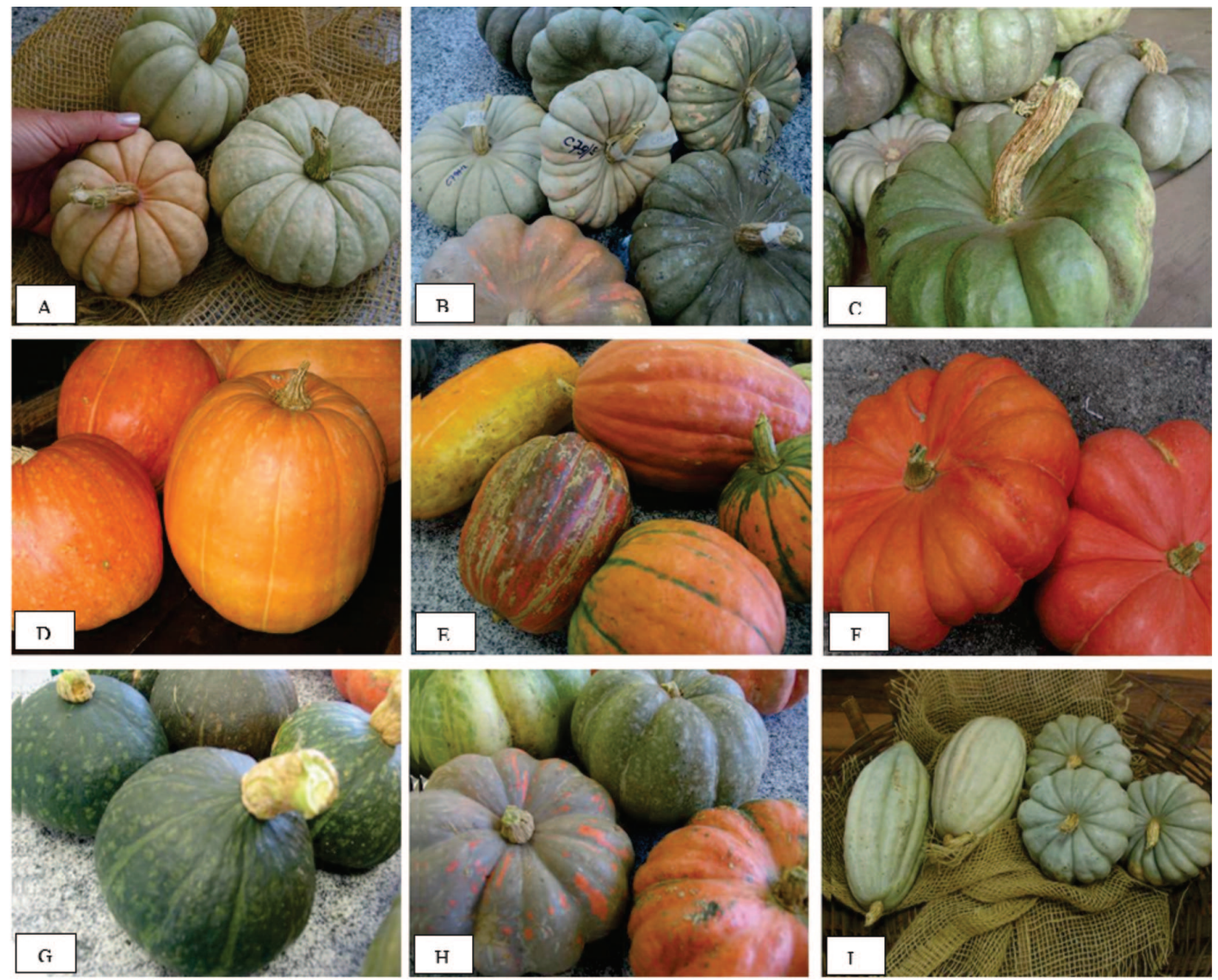

Figura 2: Variabilidade genética em variedades crioulas de Cucurbita maxima A: C8; B: C79; C: C92; D: C253; E: C269; F: C273; G: C282; H: C288; I: C347. Fotos: Daniela Priori e Rosa Lía Barbieri.

elípticos (10,3\%). Oliveira et al. (2016), ao avaliarem 14 acessos de Cucurbita moschata, coletados no norte do Estado do Rio de Janeiro, encontraram variabilidade genética para formato de frutos globulares $(35,71 \%)$, piriformes $(28,57 \%)$, elípticos $(21,43 \%)$, e cordiforme (14,29\%). Martins (2015), ao avaliar variedades locais de Cucurbita maxima da Amazônia, também encontrou variação para formato dos frutos. Entre alongados, globulares, elípticos, cordiformes e achatados, a maior frequência foi de frutos alongados e globulares.

Dentre os caracteres qualitativos avaliados, formato do pedúnculo, formato da folha e textura da casca foram monomórficos, não apresentando variação entre as variedades crioulas. As nove variedades de C. maxima foram separados em quatro grupos (Figura 3). O coeficiente de correlação cofenética entre o dendrograma e a matriz de distância genética foi elevado $(r=0,88)$. Posteriormente, foi possível identificar um ponto de corte no dendrograma, obtido pela utilização do método UPGMA com base no Índice: $\mathrm{S}_{\mathrm{ii}}=(\mathrm{C} / \mathrm{C}+\mathrm{D})$ (Figura 3$)$. O primeiro grupo foi formado pelo acesso $\mathrm{C} 8$, que ficou separado dos demais, na análise de componentes principais. O descritor espessura da casca foi o que mais influenciou para essa separação. O segundo grupo foi formado pelas variedades C79, C347, C92 e C269, sendo C79 e C347 as mais similares, com valor médio de 92,3. O terceiro grupo foi formado por C273, C 288 e C282. No quarto grupo ficou a variedade $\mathrm{C} 253$.

As variedades crioulas mais similares (C79 e C347) apresentaram as mesmas notas para os caracteres formato do caule, tamanho da folha, gomos no fruto, cor da casca predominante na maturidade, dureza da casca, cor da polpa e tamanho da semente. Mesmo apresentando esses caracteres que foram avaliados em comum, essas variedades apresentaram variações para cor e formato, em alguns frutos (Figuras 2B e 2I). Dentre as variedades que compõem o terceiro grupo está o C288 que apresenta pouca variação para tamanho e formato do fruto (Figura $2 \mathrm{H}$ ) as quais são características importantes para o melhoramento genético para uma variedade comercial. Os frutos da variedade C282 (Figura 2G) também apresentam uniformidade para formato, tamanho e coloração da casca e, con- 
Tabela 3: Moda dos 13 descritores qualitativos da planta e de frutos, em variedades crioulas de Cucurbita maxima do Banco Ativo de Germoplasma de Cucurbitáceas da Embrapa Clima Temperado

\begin{tabular}{|c|c|c|c|c|c|c|c|c|c|c|c|c|c|}
\hline Acessos & FC & FP & FF & TF & FFt & GF & CCM & CSC & DCS & TC & DC & $\mathbf{C P}$ & TS \\
\hline$\overline{\mathrm{C} 8}$ & 2 & 3 & 4 & 7 & 2 & 5 & 4 & 0 & 0 & 4 & 7 & 4 & 5 \\
\hline C79 & 1 & 3 & 4 & 7 & 2 & 5 & 10 & 0 & 0 & 4 & 5 & 4 & 5 \\
\hline C92 & 1 & 3 & 4 & 7 & 2 & 5 & 10 & 4 & 2 & 4 & 5 & 4 & 5 \\
\hline $\mathrm{C} 253$ & 1 & 3 & 4 & 7 & 1 & 3 & 12 & 4 & 2 & 4 & 3 & 3 & 7 \\
\hline C269 & 1 & 3 & 4 & 7 & 2 & 5 & 6 & 0 & 2 & 4 & 5 & 4 & 5 \\
\hline C273 & 1 & 3 & 4 & 5 & 9 & 5 & 6 & 2 & 2 & 4 & 5 & 4 & 5 \\
\hline C282 & 1 & 3 & 4 & 5 & 2 & 0 & 2 & 2 & 2 & 4 & 5 & 4 & 5 \\
\hline C288 & 1 & 3 & 4 & 5 & 1 & 5 & 10 & 2 & 2 & 4 & 5 & 4 & 5 \\
\hline C347 & 1 & 3 & 4 & 7 & 9 & 5 & 10 & 0 & 0 & 4 & 5 & 4 & 5 \\
\hline
\end{tabular}

$\mathbf{F C}=$ Formato do caule em secção transversal (1: arredondado; 2: angular); FP = formato do pedúnculo (3: arredondado; $)$ FF = formato da folhas (4: retusa); $\mathbf{T F}=$ tamanho da folha (5: intermediária; 7: grande); $\mathbf{F F t}=$ formato do fruto (1: globular; $2:$ achatado; $7:$ periforme; 9 : alongado; 14: pescoço torto); $\mathbf{G F}=$ gomos no fruto (0: ausente; 3: superficiais; 5 : intermediários; 7: profundos); CCM = cor da casca predominante na maturidade (2: verde; 4: creme; 6: laranja; 10: cinza; 12: salmão); CSC = cor secundária da casca (0: sem cor secundária; 2: verde; 4: creme; 6: laranja; 9: salmão); DCS = desenho produzido pela cor secundária (0: sem cor secundária; 2: manchado - manchas maiores que $0,5 \mathrm{~cm} ; 4$ : estriado - marcas alongadas que não são contínuas de uma extremidade do fruto a outra e têm menos de 4 cm em comprimento); $\mathbf{T C}=$ textura da casca (4: superficialmente ondulada); DC = dureza da casca (5: intermediária - difícil de marcar com a unha; 7: dura - impossível de marcar com a unha); CP = cor da polpa (3: amarela; 4: laranja); TS = tamanho da semente (5: intermediário; 7: grande).

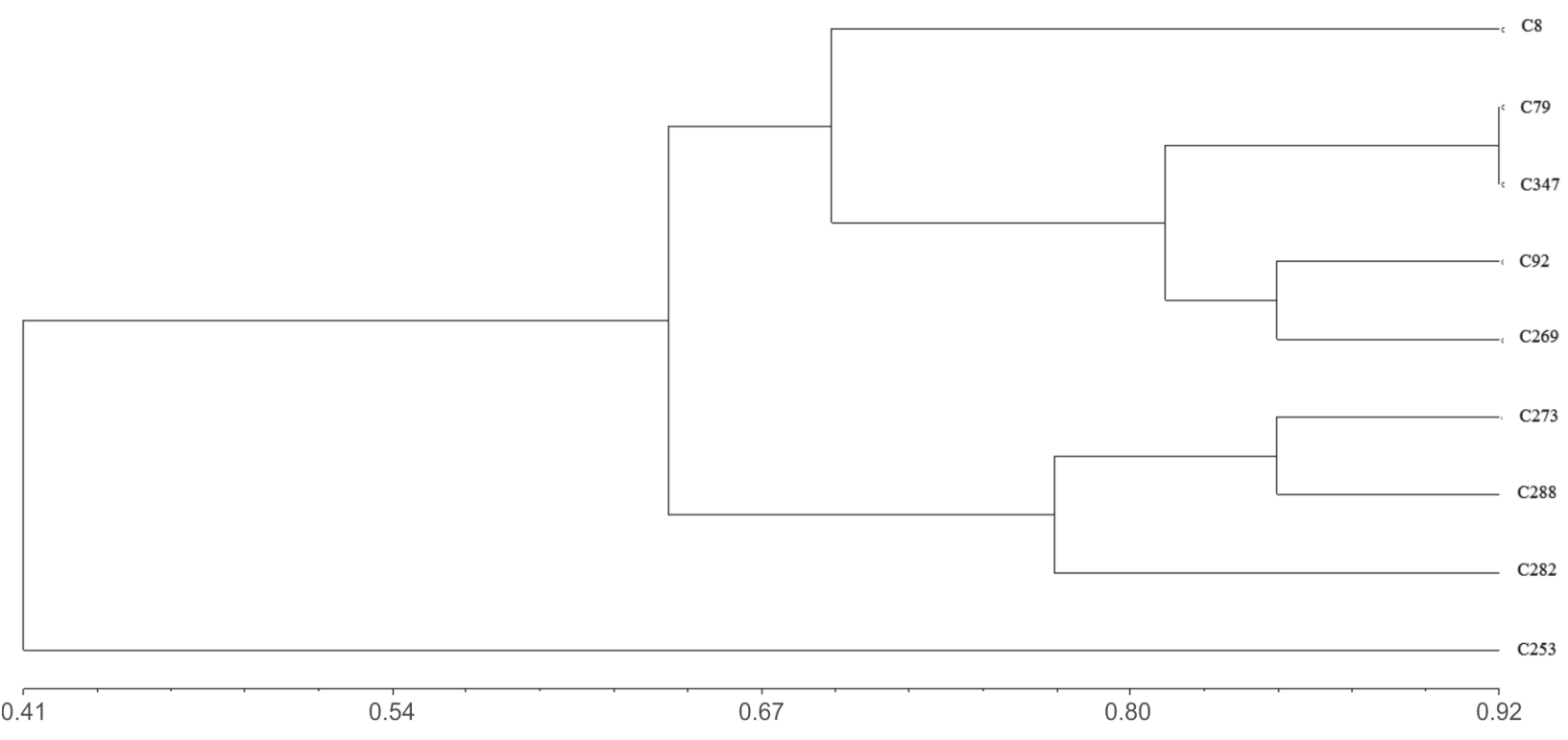

Figura 3: Dendrograma de similaridade genética entre variedades crioulas de $C$. maxima, com base em 13 caracteres qualitativos, gerado pelo método de agrupamento UPGMA, com base no Índice: $\mathrm{S}_{\mathrm{ii}}=(\mathrm{C} / \mathrm{C}+\mathrm{D})$, em que $\mathrm{C}$ é total de concordância de categorias para todas as variáveis consideradas e, D, total de discordância de categoria para todas as variáveis consideradas. Valor do coeficiente de correlação cofenética $(r)=0,88$.

forme os dados de passaporte e informações do doador, essa variedade crioula apresenta boa consistência da polpa e bom sabor.

Os resultados obtidos neste trabalho evidenciam a seleção recorrente realizada pelos agricultores familiares, que cultivam e mantêm essas variedades crioulas, resultando nas diferentes variedades por eles selecionadas. A variabilidade genética das variedades crioulas foi observada com base em caracteres morfológicos qualitativos e quantitativos, submetidos às análises de componentes principais, a teste de médias e de similaridade pelo método UPGMA. A partir dessas análises, foi possível destacar que peso, formato, cor do fruto, espessura da casca e número de sementes por fruto são caracteres relevantes para indicar variedades promissoras para o melhoramento genético, com potencial para uso como fontes de genes, visando ao desenvolvimento de cultivares com maior produtividade e direcionados a determinados segmentos de mercado.

\section{CONCLUSÕES}

Existe variabilidade genética para os caracteres, tanto quantitativos quanto qualitativos, estudados em variedades crioulas de Cucurbita maxima do Banco Ativo de 
Germoplasma de Cucurbitáceas, da Embrapa Clima Temperado.

A variedade crioula C8 (cadastrada no Registro Nacional de Cultivares como cultivar BRS Tortéi) apresenta a maior produtividade e o menor tamanho de fruto dentre os demais genótipos avaliados.

A variedade C253 apresenta maior tamanho e peso de fruto.

As variedades C79 e C347 são similares, enquanto C8 e C253 são bastante contrastantes entre si.

\section{AGRADECIMENTOS}

Os autores agradecem à CAPES e ao CNPq, pelo apoio financeiro e à Embrapa Clima Temperado, pelo apoio técnico.

\section{REFERÊNCIAS}

Almeida AHB, Pedrosa JF, Nogueira ICC \& Negreiros MZ (1994) Avaliação de cultivares e híbridos de Cucurbita maxima Duch. e Cucurbita moschata Duch. na microrregião salineira do Rio Grande do Norte. Caatinga, 8:45-48.

Alves RM (2002) Caracterização genética de populações de cupuaçuzeiro, Theobroma grandiflorum (Will ex Spreng) Schum., por marcadores microssatélites e descritores botânicoagronômicos. Tese de Doutorado. Universidade de São Paulo, Piracicaba. 146p.

Amaro GB, Carmona PAO, Carvalho ADF, Lopes JF \& Coimbra KG (2014) Desempenho de híbridos de abóboras e morangas avaliados no Distrito Federal. Horticultura Brasileira, 31:19161923.

Balkaya A, Özbakir M \& Kurtar ES (2010) The phenotypic diversity and fruit characterization of winter squash (Cucurbita maxima) populations from the Black Sea Region of turkey. African Journal of Biotechnology, 9:152-162.

Barbieri RL (2012) A diversidade de abóboras no Brasil e sua relação histórica com a cultura. Disponível em: <http:// www.slowfoodbrasil.com/textos/alimentacao-e-cultura/501aboboras-e-cultura>. Acessado em: 19 de maio de 2017.

Barbosa GS (2009) Desempenho agronômico, caracterização morfológica e polínica de linhagens de abóbora (Cucurbita moschata) com potencial para o lançamento de cultivares. Dissertação de Mestrado. Universidade Estadual do Norte Fluminense Darcy Ribeiro, Campos dos Goytacazes. 110p.

Borges RME, Resende GM, Lima MAC, Dias RCS, Lubarino PCC, Oliveira RCS \& Gonçalves NPS (2011) Phenotypic variability among pumpkin accessions in the Brazilian semiarid. Horticultura Brasileira, 29:461-464.

Blank AF, Silva TB, Matos ML, Carvalho Filho JLS \& Silva-Mann R (2013) Parâmetros genotípicos, fenotípicos e ambientais para caracteres morfológicos e agronômicos em abóbora. Horticultura Brasileira, 31:106-111.

Cabral PDS, Soares TCB, Gonçalves LSA, Amaral Júnior AT, Lima ABP, Rodrigues R \& Matta FP (2010) Quantification of the diversity among common bean accessions using Ward-MLM strategy. Pesquisa Agropecuária Brasileira, 45:1124-1132.

Carvalho PGB, Peixoto AAP \& Ferreira MAJF (2011) Caracterização de abóboras quanto aos teores de carotenoides totais, alfa- e beta-caroteno. Brasília, Embrapa Hortaliças. 20p.
Cruz CD (2013) Genes - a software package for analysis in experimental statistics and quantitative genetics. Acta Scientiarum Agronomy, 35:3:271-276.

Dias LAS, Kageyama PY \& Castro GCT (1997) Divergência genética multivariada na preservação de germoplasma de cacau (Theobroma cacao L.). Agrotrópica, 9:29-40.

Esquinas-Alcazar JT \& Gulick PJ (1983) Genetic resources of Cucurbitaceae: a global report. Roma, IBPGR. 101p.

Ferreira MAJF (2008) Abóboras e morangas. In: Barbieri \& Stumpf ERT (Eds.) Origem e evolução de plantas cultivadas. Brasília, Embrapa Informação Tecnológica. 909p.

Ferriol M, Pico MB \& Nuez F (2003) Genetic diversity of some accesisons of Cucurbita maxima from Spain using RAPD and SBAP markers. Genetic Resources and Crop Evolution, 50:227238.

Fischer SZ, Barbieri RL, Peil RMN, Stumpf ERT, Neitzke RS, Vasconcelos CS \& Treptow RO (2015) Abóboras ornamentais: atributos valorizados por consumidores finais e decoradores florais. Horticultura Brasileira, 33:480-487.

Fischer SZ, Barbieri RL, Peil RMN, Stumpf ERT, Neitzke RS, Vasconcelos CS \& Treptow RO (2016) Cultivo e uso de variedades crioulas de abóboras ornamentais no Rio Grande do Sul. Horticultura Brasileira, 34:398-404.

Fischer SZ (2012) Caracterização morfológica, etnografia e potencialidade para uso ornamental de variedades crioulas de abóboras do Rio Grande do Sul. Tese de Doutorado. Universidade Federal de Pelotas, Pelotas. 117p.

Geleta LF, Labuschagne MT \& Viljoen CD (2005) Genetic variability in pepper (Capsicum annuum L.) estimated by morphological data and amplified fragment length polymorphism markers. Biodiversity and Conservation, 14:2361-2375.

Guzmán MAV (2006) Situación actual y perspectivas del zapallo chileno camote (Cucurbita maxima): germoplasma, prácticas agronómicas y análisis económico del cultivo. Lisboa, Investigacion Agrícola. 149p.

Heiden G, Barbieri RL \& Neitzke RS (2007) Chave para identificação das espécies de abóboras (Cucurbita, Cucurbitaceae) cultivadas no Brasil. Pelotas, Embrapa Clima Temperado. 31p. (Documentos, 197).

Hernandez SM, Merrick CL \& Eguilarte L (2005) Maintenance of squash (Cucurbita spp.) landrace diversity by farmers activities in México. Genetic Research Crop Evolution, 52:697-707.

Lima GKL (2013) Resgate e estudo de germoplasma de Cucurbita spp. do Rio Grande do Norte. Tese de Doutorado. Universidade Federal Rural do Semi-Árido, Mossoró. 157p.

Lira-Saade RL (1995) Estudios taxonómicos y ecogeográficos de las Cucurbitaceae latinoamericanas de importancia económica. Rome, IPIGRI. 281p. (Systematic and Ecogeographic Studies on Crop Genepools, 9).

Marreiros A, Souza B, Andrade L, Quedas F, Leitão J, Veiga I \& Marcelino D (2005) Avaliação de populações locais de abóbora menina (Cucurbita maxima Duch. Lam). In: V Congresso Ibérico de Ciências Hortícolas, Melhoramento, recursos genéticos e biotecnologia, pós-colheita e qualidade, Lisboa. Anais, Actas Portuguesas de Horticultura. p.127-134.

Martins LHP (2015) Variabilidade genética e conservação de Cucurbita maxima Duchesne pela agricultura familiar na Amazônia centro-ocidental. Tese de Doutorado. Universidade Federal do Amazonas, Manaus. 151p.

Nick C \& Borém A (2017) Abóboras e morangas: do plantio à colheita. Viçosa, UFV. 203p.

Rev. Ceres, Viçosa, v. 65, n.4, p. 337-345, jul/ago, 2018 
Nascimento WM, Coimbra KG, Freitas RA \& Boiteux LS (2008) Eficiência de acessos de Cucurbita maxima como polinizadores de abóbora híbrida do tipo "Tetsukabuto". Horticultura Brasileira, 26:540-542.

Neitzke RS, Barbieri RL, Heiden G, Büttow MV, Oliveira CS, Corrêa LB, Schwengber JE \& Carvalho FIF (2009) Caracterização morfológica e dissimilaridade genética entre variedades crioulas de melão. Horticultura Brasileira, 27:534-538.

Nerson H, Paris HS \& Paris EP (2000) Fruit shape, size and seed yield in Cucurbita pepo. Acta Horticulturae, 510:227-230.

Oliveira RL, Gonçalves LSA, Rodrigues R, Baba VY, Sudré CP, Santos MH \& Aranha FM (2016) Genetic divergence among pumpkin landraces. Semina: Ciências Agrárias, 37:547-556.

Paksoy M \& Aydin C (2004) Some physical properties of edible squash (Cucurbita pepo L.) seeds. Journal of Food Engineering, 65:225-23.

Priori D, Barbieri RL, Castro CM, Oliveira AC, Vilella JCB \& Mistura CC (2012) Caracterização molecular de variedades crioulas de abóboras com marcadores microssatélites. Horticultura Brasileira, 30:499-506.

Priori D, Barbieri RL, Castro CM, Oliveira AC, Villela JCB \& Mistura CC (2013) Diversidade genética de Cucurbita pepo, C. argyrosperma e $C$. ficifolia empregando marcadores microssatélites. Horticultura Brasileira, 31:361-368.

Priori D (2011) Caracterização molecular de recursos genéticos de Cucurbita argyrosperma, Cucurbita ficifolia e Cucurbita pepo. Dissertação de Mestrado. Universidade Federal de Pelotas, Pelotas. $78 \mathrm{p}$.

Priori D (2015) Recursos genéticos de abóboras: usos, caracterização e avaliação do fluxo gênico. Tese de Doutorado. Universidade Federal de Pelotas, Pelotas. 116p.

Priori D, Valduga E, Villela JCB, Mistura CC, Vizzotto M, Valgas RA \& Barbieri RL (2017) Characterization of bioactive compounds, antioxidant activity and minerals in landraces of pumpkin (Cucurbita moschata) cultivated in Southern Brazil. Food Science and Technology, 37:33-40.

R Development Core Team (2011) R: A language and environment for statistical computing. R Foundation for Statistical Computing, Vienna, R Foundation for Statistical Computing. Disponível em: <http://www.R-project.org/>. Acessado em: 14 de março de 2017.
Ramos SSR, Lima NRS, Carvalho HWL, Oliveira IR \& Sobral FS (2010a) Curado FF Aspectos técnicos do cultivo da abóbora na região Nordeste do Brasil. Aracaju, Embrapa Tabuleiros Costeiros. 36p. (Documentos, 154).

Ramos SRR, Queiroz MA, Casali VWD \& Cruz CD (2010b) Recursos genéticos de Cucurbita moschata: caracterização morfológica de populações locais coletadas no Nordeste brasileiro. In: Queiróz MA, Goedert CO \& Ramos SRR (Eds.) Recursos genéticos e melhoramento de plantas para o Nordeste brasileiro (on line). Petrolina, Embrapa Semi-Árido / Brasília, Embrapa Recursos Genéticos e Biotecnologia. Disponível em: <http://www.cpatsa.embrapa.br:8080/catalogo/livrorg/ abobora.pdf $>$. Acessado em: 21 de maio de 2018.

Rohlf FJ (1989) NTSYS-pc: numerical taxonomy and multivariate analysis system. Version 2.02e. New York, Applied Biostatistics Inc. CD-ROM.

Santos JO (2013) Adaptabilidade e estabilidade de pré-cultivares de abóbora (Cucurbita moschata D.) nas condições do norte e do Noroeste Fluminense. Tese de Doutorado. Universidade Estadual do Norte Fluminense Darcy Ribeiro, Campos dos Goytacazes. 28p.

SAS Institute (2008) SAS statistical software: Release 9.2. Cary, SAS Institute. 266p.

Sudré CP, Gonçalves LSA, Rodrigues R, Amaral Júnior AT, RivaSouza EM \& Bento CS (2010) Genetic variability in domesticated Capsicum spp. as assessed by morphological and agronomic data in mixed statistical analysis. Genetics and Molecular Research, 9:283-294.

Torres Filho J (2008) Caracterização morfo-agronômica, seleção de descritores e associações entre a divergência genética e a heterose em meloeiro. Tese de Doutorado. Universidade Federal Rural do Semi-Árido, Mossoró. 150p.

Whitaker TW \& Robinson RW (1986) Squash breeding. In: Bassett MJ (Ed.) Breeding Vegetable Crops. Westport, Avi publishing. p.209-242.

Yan W (2001) GGEbiplot - A Windows application for graphical analysis of multienvironment trial data and other types of twoway data. Agronomy Journal, 93:1111-1118. 